\title{
Extracellular matrix molecules as targets for brown spider venom toxins
}

\section{S.S. Veiga ${ }^{1}$, V.C. Zanetti ${ }^{1}$, \\ A. Braz' ${ }^{1}$ O O.C. Mangili ${ }^{2}$ and W. Gremski ${ }^{1}$}

Departamentos de ${ }^{1}$ Biologia Celular, and ${ }^{2}$ Fisiologia,

Universidade Federal do Paraná, Curitiba, PR, Brasil

\section{Correspondence \\ S.S. Veiga \\ Departamento de Biologia Celular Universidade Federal do Paraná 81531-990 Curitiba, PR \\ Brasil \\ Fax: + 55-41-266-2042 \\ E-mail: veigass@bio.ufpr.br \\ Research supported by CNPq, CAPES, Fundação Araucária-PR and FUNPAR-UFPR.}

Received September 12, 2000 Accepted April 17, 2001

\section{Abstract}

Loxoscelism, the term used to describe lesions and clinical manifestations induced by brown spider's venom (Loxosceles genus), has attracted much attention over the last years. Brown spider bites have been reported to cause a local and acute inflammatory reaction that may evolve to dermonecrosis (a hallmark of envenomation) and hemorrhage at the bite site, besides systemic manifestations such as thrombocytopenia, disseminated intravascular coagulation, hemolysis, and renal failure. The molecular mechanisms by which Loxosceles venoms induce injury are currently under investigation. In this review, we focused on the latest reports describing the biological and physiopathological aspects of loxoscelism, with reference mainly to the proteases recently described as metalloproteases and serine proteases, as well as on the proteolytic effects triggered by L. intermedia venom upon extracellular matrix constituents such as fibronectin, fibrinogen, entactin and heparan sulfate proteoglycan, besides the disruptive activity of the venom on Engelbreth-Holm-Swarm basement membranes. Degradation of these extracellular matrix molecules and the observed disruption of basement membranes could be related to deleterious activities of the venom such as loss of vessel and glomerular integrity and spreading of the venom toxins to underlying tissues.

\author{
Key words \\ - Brown spider \\ - Venom \\ - Extracellular matrix \\ - Proteolytic effect
}

\section{Introduction}

Brown spiders (Loxosceles genus) have been reported to cause several clinical manifestations. Envenomation provokes two major kinds of signals, i.e., local lesions at the bite site characterized by edema followed by vasodilatation, blood vessel degeneration, local hemorrhage and a significant cutaneous tissue injury with gravitational spreading, that can exacerbate to necrotic skin ulcers and degeneration (1-4), and systemic effects that begin as a malaise and can become generalized, with hemolysis, thrombocytopenia, disseminated intravascular coagulation and renal failure. These clinical signs and toxicological effects appear to be phenomena similar for several Loxosceles species including the more studied $L$. reclusa, $L$. laeta, L. intermedia and L. gaucho species (4-8).

Brown spider venoms are highly complex and contain many different proteins (911). The exact mechanisms by which the 
venoms cause their deleterious effects are currently under investigation, with putative explanations involving an indirect event, as is the case for endothelial cell-dependent neutrophil activation caused by the venoms and seemingly related to the dermonecrotic lesion (4,12-14). The presence of a sphingomyelinase D-like enzyme (32-35 kDa) probably associated with necrotic, hemolytic and thrombocytopenic activities triggered by the venoms has also been identified in different Loxosceles species $(3,4,6,10,15,16)$. Other enzymes such as a hyaluronidase have been postulated to be a spreading factor during the lesions $(4,17)$, and protease activities also appear to have some participation in the noxious effects of the venoms $(11,18-21)$. Adult plasma components appear to be required for the deleterious effects of the venoms, since a purified putative dermonecrotic toxin diluted in neonate plasma or synthetic buffer did not induce platelet activation, an event that may be responsible for thrombosis, tissue ischemia and dermonecrosis (8). Indirectly, venoms also seem to cause injury by binding to cell membranes and activating the complement system of plasma $(8,22,23)$ (see Table 1$)$.

The key observations that some physi- ological events closely dependent on the basement membrane and on connective or plasma extracellular matrix constituents are altered during loxoscelism, as is the case for platelet subendothelial adhesion and aggregation, hemostatic troubles such as disseminated intravascular coagulation, hemorrhage into the dermis, renal failure and even cutaneous tissue injury, point to the presence of molecules potentially deleterious to these structures in the venoms.

This review focuses on the specific degrading effects triggered by Loxosceles venoms in extracellular matrix molecules and the biological consequences of these hydrolytic activities related to the clinical signs induced by loxoscelism.

\section{Presence of gelatinolytic enzymes in L. intermedia venom}

Several extracellular matrix molecules have been described as targets for degradation evoked by proteases present in snake venoms, which cause hemorrhage, necrosis and edema (24-28). Soluble plasma fibrinogen is the major substrate in this family, but it is not the only one since snake venom actions on laminin, entactin, fibronectin and

Table 1. Brown spider venom properties.

\begin{tabular}{lll}
\hline Venom effects & Molecules involved & References \\
\hline Dermonecrotic lesion & $32 \mathrm{kDa}++, 35 \mathrm{kDa}+,+++$ & $3,4,8,10,16,22$ \\
Intravascular hemolysis & $32 \mathrm{kDa}++, 35 \mathrm{kDa}+$ & $4,6,16,22$ \\
Platelet aggregation and thrombocytopenia & $32 \mathrm{kDa}++, 35 \mathrm{kDa}+$ & $4,8,15$ \\
Gravitational spreading & $33 \mathrm{kDa}++, 63 \mathrm{kDa}++$ & 4,17 \\
Fibrinogenolytic activity & $20-28 \mathrm{kDa}+$ & 19 \\
Fibronectinolytic activity & $20-28 \mathrm{kDa}+$ & 19 \\
Gelatinolytic activity & $32-35 \mathrm{kDa}+, 85 \mathrm{kDa}+, 95 \mathrm{kDa}+$ & $11,19,20$ \\
Entactinolytic activity & Unknown+ & 21,57 \\
Basement membrane-degrading effect & Unknown+ & 21,57 \\
Complement system activation & $32 \mathrm{kDa}++, 35 \mathrm{kDa}+$ & $4,16,22,23$ \\
Heparan sulfate proteoglycan hydrolysis & Unknown+ & 21
\end{tabular}

Dermonecrotic lesion, intravascular hemolysis, platelet aggregation and complement system activation are events dependent on the similar brown spider toxins of 32-35 kDa devoid of proteolytic activities. The 32-35-kDa molecule with gelatinolytic activity is a metalloprotease.

Results obtained by using Loxosceles intermedia venom (+), L. reclusa venom (++), and L. gaucho venom $(+++)$. 
gelatin have been described $(24,29)$. With respect to spider venoms and despite some similarities to snake venoms in their activities, little is known about the presence of venom proteases that degrade extracellular matrix molecules. Studying L. intermedia venom (the prevalent brown spider in southern Brazil) we were able to detect a 32-35$\mathrm{kDa}$ metalloprotease with gelatinolytic activity. The 35-kDa protease form seems to be a latent pro-enzyme molecule that undergoes cleavage, originating the $32-\mathrm{kDa}$ form (19). The 32-35-kDa proteases are high-mannose glycoproteins (20). We also detected zymogen molecules of proteolytic enzymes in the venom since trypsin activated two gelatinolytic serine proteases of 85 and 95 $\mathrm{kDa}$ in the venom. Other proteins such as casein, albumin, hemoglobin and laminin did not suffer any kind of cleavage. The specificity of action of these proteases should be related to spider self-protection. For example, the venom gland of $L$. intermedia is extremely rich in laminin, which separates muscle tissue (involved in venom secretion) from epithelial cells (involved in venom synthesis) (30), and the venom seems to have no lamininolytic activity $(19,21)$. The natural substrate of the $32-35-\mathrm{kDa}$ protease is unknown (since gelatin is denatured collagen and the venom does not display any activity on full length collagen), but, based on gelatinolytic activity, we may assume that this protease has properties like vertebrate gelatinases that appear to cleave connective components (31) and we may propose that this brown spider enzyme is functionally related to the deleterious effects of the venom. Native collagen can suffer an initial effect of collagenase from polymorphonuclear neutrophil leukocytes (which, as described above, are concentrated at the bite site and around it and seem to play a role in dermonecrosis), partially denaturating this molecule, which then can be sequentially degraded by these gelatinase-like venom proteases (see Table 1).

\section{Effect of Loxosceles venom proteases on plasma extracellular matrix molecules}

Brown spider envenomation, although causing classical skin degeneration, is also responsible for disorders of hemostasis such as hemorrhage into the dermis and disseminated intravascular coagulation. The hemorrhage mechanism has not been fully established at the molecular level. Plasma extracellular matrix molecules are multifunctional proteins involved in blood coagulation on the basis of their ability to bind heparin, as is the case for fibronectin and vitronectin (3234 ), to interact with plasminogen, plasminogen activator inhibitors and the thrombinantithrombin III complex, as is the case for vitronectin $(33,35,36)$, and to promote platelet adhesion and aggregation, as is the case for fibrinogen, fibronectin, von Willebrand factor and thrombospondin (25,28,37-39). They also mediate fibrin formation as fibrinogen $(38,39)$. L. intermedia venom degrades both the A and B chains of fibronectin (Figure 1) into a variety of smaller fragments $(19,20)$, and partially digests fibrinogen (Figure 1) (19,20), but, interestingly, has no proteolytic activity on soluble vitronectin (see Figure 1). This fibrinogenolytic effect is closely similar to that of other brown spider venoms ( $L$. gaucho and L. laeta) (Zanetti $\mathrm{VC}$, unpublished results). The fibronectinolytic and fibrinogenolytic activities of $L$. intermedia venom are produced by a metalloprotease of 20-28 $\mathrm{kDa}$ (19). Based on the biological activities of brown spider venoms, we may postulate a relationship of this fibronectinolytic effect of the venom with hemorrhage and difficulties in wound healing. The hemorrhage into the dermis at the bite site, vasodilatation and injury to blood vessel walls could be associated with defective fibronectin surrounding the endothelial cells of capillaries. The hemorrhage could also be related to imperfect platelet adhesion and aggregation, since fibronectin partici- 
pates in platelet attachment and aggregation and the proteolytic effect of the venom may disturb this event. Finally, the defective wound healing observed in some cases of envenomation may also be ascribed to the fibronectinolytic activity of the venom, since fibronectin-integrin interactions participate in an essential manner in this phenomenon (32). An identical hypothesis could be raised for the fibrinogenolytic ability of brown spider venom, since it has been well defined that several snake venom proteases with hemorrhagic activities readily degrade fibrinogen-fibrin into nonclotting fragments

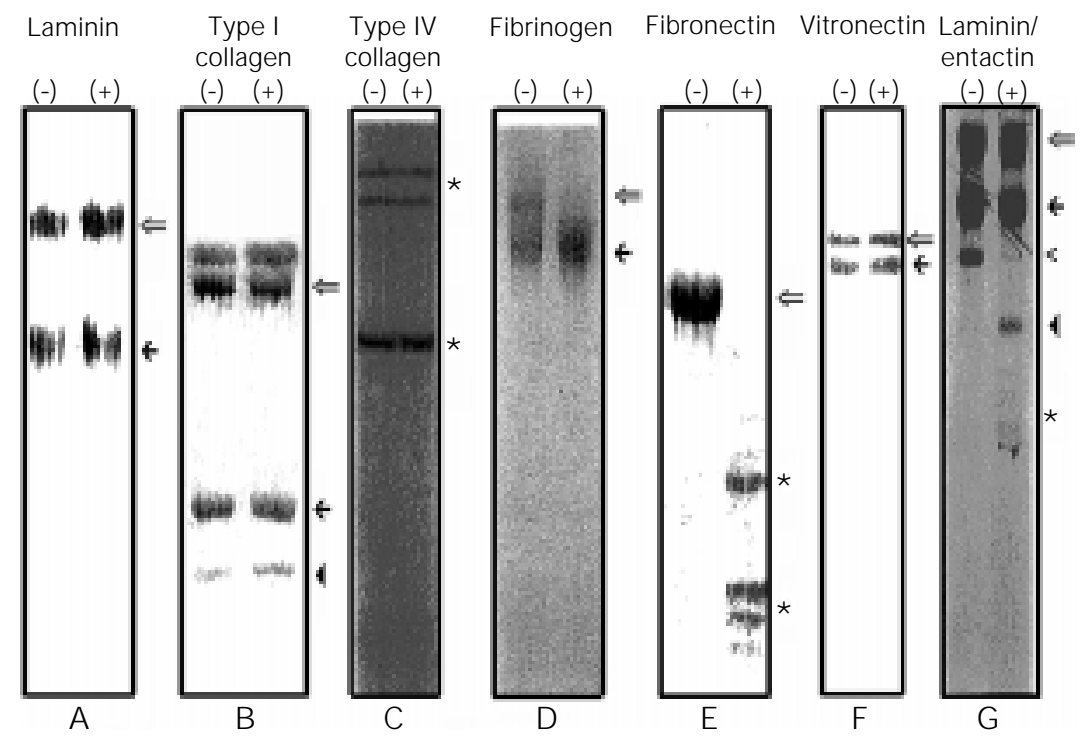

Figure 1. Proteolytic effect of Loxosceles intermedia venom on purified extracellular matrix molecules*. EHS-laminin (A), rat tail tendon type I collagen (B), human placental type IV collagen $(C)$, human fibrinogen (D), human fibronectin $(E)$, human vitronectin $(F)$ and EHSlaminin/entactin dimer $(G)$ were incubated with venom $(+)$ or in the absence of venom, as controls for experimental stability (-) under the conditions described in References 19, 20, 21 and 57 . The products obtained were analyzed by SDS-PAGE under reducing conditions (except for fibrinogen that was analyzed under nonreducing conditions). In panel A the open arrow indicates the laminin $\alpha_{1}$ chain and the filled arrow indicates the $\beta_{1}$ and $\gamma_{1}$ laminin chains that co-migrate. In panel B the open arrow indicates the type I collagen $ß$ dimers, the filled arrow depicts $\alpha_{1}$ type I collagen chain and the filled arrowhead indicates the $\alpha_{2}$ type I collagen chain. In panel $\mathrm{C}$ the asterisks represent the major components of trypsin-extracted human placental type IV collagens of 100, 160 and $170 \mathrm{kDa}$. In panel D the open arrow points to an intact fibrinogen molecule and the filled arrow indicates the fibrinogen fragment. In panel $E$ the open arrow shows the co-migratory fibronectin A and B chains, and asterisks indicate fibronectin fragments. In panel $F$ the open arrow points to the 75-kDa vitronectin molecule and the filled arrow points to the 65-kDa normally processed vitronectin fragment. In panel $G$ the open arrow indicates the laminin $\alpha_{1}$ chain, the filled arrow indicates the $\beta_{1}$ and $\gamma_{1}$ laminin chains that co-migrate, the open arrowhead indicates intact entactin, the filled arrowhead indicates the $100-\mathrm{kDa}$ entactin fragment, and the asterisk shows the 50-kDa entactin fragment. *Based on results from References 19, 20, 21 and 57.
$(26,27,40)$. Disseminated intravascular coagulation is a clinical feature detected in a few cases of brown spider envenomation. Venoms from various snakes that partially degrade fibrinogen provoke disseminated intravascular coagulation by fibrin formation $(25,28)$. As previously postulated by Bascur et al. (7) and corroborated by Feitosa et al. (19) and Veiga et al. (20), on the basis of partial fibrinogenolytic activity triggered by brown spider venoms, we may speculate that this ability is involved in disseminated intravascular coagulation, a complication that, together with other hematologic disturbances, has been responsible for most of the deaths due to loxoscelism.

Fibrinogen is a large glycoprotein (340 $\mathrm{kDa}$ ) formed by dimeric linking of three distinct chains, $\mathrm{A} \alpha, \mathrm{B} \beta$ and $\gamma$, linked by disulfide bridges. As described above, fibrinogen $A \alpha$ chains are degraded by the venoms. It is interesting to observe that the $\alpha$ chains of fibrinogen have two RGD sequences, a peptide well defined as a major binding site for several integrins (41). The cleaving of fibrinogen RGD sequences by the venoms could reduce the interaction of integrin $\alpha_{\mathrm{IIb}} \beta_{3}$ on the platelet surface with fibrinogen, resulting in the loss of platelet adhesion and functional aggregation and contributing to the hemorrhagic effect of the venom. We may suggest this proteolysis as a conservative event for Loxosceles species, indicating some biological function related to the life cycle and envenomation of brown spiders (see Table 1).

\section{Action of brown spider venom on basement membrane constituents}

The basement membranes are ubiquitous specialized forms of extracellular matrices produced by several cell types such as endothelial, epithelial, fat, muscle and nervous cells. Molecularly they are characterized by the presence of a considerable variety of biochemically complex components arranged 
as a network and formed by a particular set of proteins such as laminin, entactin, type IV collagen and heparan sulfate proteoglycan. Despite their tissue specificity (different isoforms), these components are present on practically all tissue basement membrane structures. In mammals, basement membranes play several essential roles in angiogenesis, cell differentiation, platelet adhesion, neuritogenesis, and blood-urine filtration through the kidney glomeruli, among several other functions (42-46). The effects of venom toxins on basement membranes have been well established for some snake venom hemorrhagic proteases that produce proteolytic degradation of basement membrane constituents isolated from EngelbrethHolm-Swarm (EHS) tumor $(29,40)$, as well as degradation of purified glomerular basement membrane (47). The pathogenic properties of Loxosceles venoms, such as dermonecrotic action, thrombocytopenic activity, local hemorrhage and renal disorders, are events attributable to the presence of proteolytic enzymes that degrade basement membrane molecules. By using the EHS tumor, a transplantable model which produces a characteristic and thick basement membrane as its capsule (48), we detected a disruptive activity of $L$. intermedia venom toward basement membrane structures. The venom apparently has no activity on laminin or type IV collagen (see Figure 1), the major macromolecules of these structures, but has the ability to hydrolyze entactin $(19,21)$, a dumbbell-shaped molecule that links laminin, type IV collagen and heparan sulfate proteoglycan in the basement membrane organization $(42,43)$. The hydrolytic activity of $L$. intermedia venom on entactin resulted in fragments of approximately 100 and $50 \mathrm{kDa}$ when entactin was complexed to laminin and lower fragments that run out the gel when purified entactin was assayed (21). Similar results concerning this differential entactin susceptibility to the venom have been reported for other venoms such as snake venom toxins $(29,40)$. This difference in cleavage profile for purified entactin and for the laminin-entactin complex treated with $L$. intermedia venom can be explained by the fact that laminin interacting with entactin can hide domains of entactin more susceptible to the degrading action of the venom, as previously described for the entactinolytic effect evoked by atrolysins, metalloproteases from Crotalus atrox snake venom (40).

Another essential family of molecules involved in basement membrane assembly and biological activities are the proteoglycans, complex molecules formed by a protein core to which one or more glycosaminoglycan chains are linked $(49,50)$. They have been involved in several biological effects such as extracellular matrix organization $(42,43)$, they are extracellular matrix cell surface receptors (51-53), play a role in cell-cell recognition (54), control cell growth and proliferation $(50,55)$, participate in blood vessel stability and hemostasis (49), and have several other functions (49-51). L. intermedia venom degrades the protein core of purified heparan sulfate proteoglycan, but has no activity on heparan sulfate polysaccharide chains (21). On the other hand, the venom degrades chondroitin sulfate polysaccharide chains (Nader HB and Dietrich CB, personal communication). An established endothelial cell line from rabbit aorta (56) submitted to the presence of $L$. intermedia venom increases the liberation of heparan sulfate proteoglycan and sulfated proteins from its extracellular matrix and cell surface into the culture medium (Nader HB and Dietrich CB, personal communication). Based on the fact that $L$. intermedia venom degrades entactin, heparan sulfate protein core, and chondroitin sulfate polysaccharide chains, and releases laminin from basement membranes and that these molecules are extremely important for the structural and functional properties of basement membranes, we may speculate that these effects of the venom are plausible mechanisms for several deleterious conse- 
quences of envenomation (see Table 1).

\section{Concluding remarks and future expectations}

The molecular mechanisms by which the brown spider venoms cause dermonecrotic injury, local and systemic hemorrhage, thrombocytopenia, hemolysis, disseminated intravascular coagulation and renal failure are currently under investigation, but since the venom is composed of a mixture of several proteins, these mechanisms seem to be molecularly complex and may be dependent on many different toxins.

In the present review, based on previous results obtained by our group $(11,19-21,57)$, we introduce the idea of venom toxins acting as proteases upon molecular constituents of plasma extracellular matrix such as fibronectin and fibrinogen and basement membrane constituents such as entactin and heparan sulfate proteoglycan. Based on these degrading activities on plasma constituents and the disruptive effect on basement membrane structures triggered by venoms, we may speculate that these activities are plausible mechanisms for hemorrhage, delayed wound healing and renal failure and are also related to the spreading of other noxious toxins (for example, dermonecrotic protein), since disruption of the subendothelial basement membrane evokes blood vessel wall instability and increased permeability.

It is clear that more work is needed to elucidate the structure and function of these venom metalloproteases and to fully understand how they interfere with clinical signs of loxoscelism. However, it is interesting that all detected proteolytic activities and especially the disruptive effect of $L$. intermedia venom on EHS-basement membranes can be inhibited by 1,10-phenanthroline, a metalloprotease inhibitor.

On the other hand, based on biodiversity, venom toxins are excellent tools for investigating molecular mechanisms in the cell biology field, as well as for pharmaceutical applications of newly discovered medicines. In this area, venom toxins could be used as starting materials to design new drugs or directly for therapeutic use as is the case for ancrod, a defibrinogenating enzyme from Callocelasma rhodostoma venom, and batroxobin, a defibrinogenating enzyme from Bothrops atrox venom, toxins that have been used as defibrinogenating agents for a number of clinical conditions such as deep vein thrombosis, myocardial infarction, pulmonary embolus, acute ischemic stroke, angina pectoris, central retinal vein occlusion and renal transplant rejection $(27,58-60)$. With respect to the pharmaceutical applications of brown spider venom toxins, at least one possibility can emerge from our results. The fibrinogenolytic-fibrinolytic properties of venoms directly indicate that this toxin could be useful for clinical applications in cardiac and thrombotic diseases based on reduced blood fluidity. Other possibilities can directly or indirectly arise from brown spider venom toxins (for example, as a tool in cell biology procedures to study the inflammatory response). A molecular understanding of loxoscelism may greatly enhance our therapeutic approach to this envenoming problem, as well as generate potential toxins as tools for scientific protocols and medicinal applications.

\section{References}

1. Atkins J A, Wingo CW, Sodeman WA \& Flynn JE (1958). Necrotic arachnidism. American J ournal of Tropical Medicine and Hygiene, 7: 165-184.

2. Wasserman GS \& Anderson PC (1984).
Loxoscelism and necrotic arachnidism. J ournal of Toxicology. Clinical Toxicology, 21: 451-472.

3. Babcock J L, Civello DJ \& Geren CR (1981). Purification and characterization of a toxin from brown recluse spider (Loxosceles reclusa) venom gland extracts. Toxicon, 19: 677-689.

4. FutrellJ (1992). Loxoscelism. AmericanJ ournal of the Medical Sciences, 304: 261-267. 
5. Berger RS, Edward HA \& Anderson PC (1973). Intravascular coagulation: The cause of necrotic arachnidism. J ournal of Investigative Dermatology, 61: 142-150.

6. Forrester LJ , Barrett JT \& Campbell BJ (1978). Red blood cell lysis induced by the venom of the brown recluse spider. The role of sphingomyelinase $D$. Archives of Biochemistry and Biophysics, 187: 355365.

7. Bascur L, Yevenes I \& Barja P (1982). Effects of Loxosceles laeta spider venom on blood coagulation. Toxicon, 20: 795796.

8. Rees SR, Gates C, Timons S, Des-Pres RM \& King J r LE (1988). Plasma components are required for platelet activation by the toxin of Loxosceles reclusa. Toxicon, 26: 1035-1046.

9. Norment BR, J ong Y-S \& Heitz J R (1979). Separation and characterization of venom components in Loxosceles reclusa - III. Hydrolytic enzyme activity. Toxicon, 17: 539-548.

10. Barbaro KC, Cardoso J LC, Eickstedt VRD $\&$ Motal (1992). Dermonecrotic and lethal components of Loxosceles gaucho spider venom. Toxicon, 30: 331-338.

11. Veiga SS, Da Silveira RB, Dreyfuss J L, Haoach J, Pereira AM, Mangili OC \& Gremski W (2000). Identification of high molecular weight serine-proteases in Loxosceles intermedia (brown spider) venom. Toxicon, 38: 825-839.

12. Smith WC \& Micks WD (1970). The role of polymorphonuclear leukocytes in the lesion caused by the venom of the brown spider, Loxosceles reclusa. Laboratory Investigation, 22: 90-93.

13. Majeski J A, Stinnett J D, Alexander J W \& Durst GG (1977). Action of venom from the brown recluse spider (Loxosceles reclusa) on human neutrophils. Toxicon, 15 : 423-427.

14. Patel KD, Modur V, Zimmerman GA, Prescott SM \& McIntyre TM (1994). The necrotic venom of brown recluse spider induces dysregulated endothelial cell-dependent neutrophil activation. J ournal of Clinical Investigation, 94: 631-642.

15. Kurpiewski G, Forrester LJ , Barrett JT \& Campbell BJ (1981). Platelet aggregation and sphingomyelinase $D$ activity of a purified toxin from the venom of Loxosceles reclusa. Biochimica et Biophysica Acta, 678: 467-476.

16. Tambourgi DV, Magnoli FC, van den Berg CW, Morgan BP, Araujo PS de, Alves EW $\&$ Dias da Silva W (1998). Sphingomyelinases in the venom of the spider Loxosceles intermedia are responsible for both dermonecrosis and complement-dependent hemolysis. Biochemical and Biophysical Research Communications, 251: 366373.

17. Wright RP, Elgert K, Campbell BJ \& Barrett J T (1973). Hyaluronidase and esterase activities of the venom of the poisonous brown recluse spider. Archives of Biochemistry and Biophysics, 159: 415426.

18. J ong Y-S, Norment BR \& Heitz J R (1979). Separation and characterization of venom components in Loxosceles reclusa - II. Protease enzyme activity. Toxicon, 17: 529-537.

19. Feitosa L, Gremski W, Veiga SS, Elias MCQB, Graner E, Mangili OC \& Brentani RR (1998). Detection and characterization of metalloproteinases with gelatinolytic, fibronectinolytic and fibrinogenolytic activities in brown spider (Loxosceles intermedia) venom. Toxicon, 36: 1039-1051.

20. Veiga SS, Gremski W, Santos VLP, Feitosa L, Mangili OC, Nader HB, Dietrich CP \& Brentani RR (1999). Oligosaccharide residues of Loxosceles intermedia (brown spider) venom proteins: dependence on glycosylation for dermonecrotic activity. Toxicon, 37: 587-607.

21. Veiga SS, Feitosa L, Santos VLP, de Souza GA, Ribeiro AS, Mangili OC, Porcionatto MA, Nader HB, Dietrich CP, Brentani RR \& Gremski W (2000). Effect of Loxosceles intermedia (brown spider) venom on basement membrane structures. Histochemical J ournal, 32: 397-408.

22. Tambourgi DV, Magnoli FC, Eickstedt VRD, Benedetti ZC, Petricevich VL \& Silva WD (1995). Incorporation of a 35-kilodalton purified protein from Loxosceles intermedia spider venom transforms human enythrocytes into activators of autologous complement alternative pathway. J ournal of Immunology, 155: 4459-4466.

23. Tambourgi DV, Morgan BP, de Andrade RMG, Magnoli FC \& van den Berg CW (2000). Loxosceles intermedia spider envenomation induces activation of an endogenous metalloproteinase, resulting in cleavage of glycophorins from the erythrocyte surface and facilitating complement-mediated lysis. Blood, 95: 683-691.

24. Bjarnason J B \& Fox JW (1995). Snake venom metalloendopeptidases: reprolysins. Methods in Enzymology, 248: 345368.

25. Beutler E, Lichtman MA, Coller BS \& Kipps TJ (1995). Williams Hematology. 5th edn. McGraw-Hill, New York.

26. Kamiguti AS, Hay CRM, Theakston RDG \& Zuzel M (1996). Insights into the mech- anism of hemorrhage caused by snake venom metalloproteinases. Toxicon, 34 : 627-642.

27. Markland FS (1998). Snake venoms and the hemostatic system. Toxicon, 36: 1749-1800.

28. Lee GR, Foerster J , Lukens J , Paraskevas F, Greer J P \& Rodgers GM (1999). Wintrobe's Clinical Hematology. Williams \& Wilkins, Baltimore.

29. Baramova EN, Shannon J D, Bjamason J B \& Fox J W (1989). Degradation of extracellular matrix proteins by haemorrhagic metalloproteinases. Archives of Biochemistry and Biophysics, 275: 63-71.

30. Santos VLP, Franco CRC, Viggiano RLL, da Silveira RB, Cantão MP, Mangili OC, Veiga SS \& Gremski W (2000). Structural and ultrastructural description of the venom gland of Loxosceles intermedia (brown spider). Toxicon, 38: 265-285.

31. Birkedal-Hansen $\mathrm{H}$, Moore WGI, Bodden MK, Windsor LJ, Birkedal-Hansen B, DeCarlo A \& Engler J A (1993). Matrix metalloproteinases: A review. CRC Critical Reviews in Oral Biology and Medicine, 4: 197-250.

32. Ruoslahti E (1988). Fibronectin and its receptors. Annual Review of Biochemistry, 57: 375-413.

33. Felding-Habermann $B \&$ Cheresh DA (1993). Vitronectin and its receptors. Current Opinion in Cell Biology, 5: 864-868.

34. Veiga SS, Elias MCQB, Gremski W, Porcionatto MA, Nader HB \& Brentani RR (1996). Detection of post-translational sulfation of $\alpha_{5} \beta_{1}$ integrin and its role in integrin-fibronectin binding. Brazilian J ournal of Medical and Biologial Research, 29: 1235-1238.

35. Kost C, Stueber W, Ehrlich HJ , Pannekoek H \& Preissner KT (1992). Mapping of binding sites for heparin, plasminogen activator inhibitor-1, and plasminogen to vitronectin's heparin-binding region reveals a novel vitronectin-dependent feedback mechanism for the control of plasmin formation. J ournal of Biological Chemistry, 267: 12098-12105.

36. De Boer HC, Preissner KT, Bouma BN \& De Groot PG (1992). Binding of vitronectin-thrombin-antithrombin III complex to human endothelial cells is mediated by the heparin binding site of vitronectin. J ournal of Biological Chemistry, 267: 2264-2268.

37. Wencel-Drake J D, Painter RG, Zimmerman TS \& Ginsberg MH (1985). Ultrastructural localization of human platelet thrombospondin, fibrinogen, fibronectin and von Willebrand factor in frozen thin 
section. Blood, 4: 929-938.

38. Ruggeri ZM (1992). Von Willebrand factor and fibrinogen. Current Opinion in Cell Biology, 5: 898-906.

39. Farrell DH, Thiagarajan $P$, Chung DW \& David EW (1992). Role of fibrinogen $\alpha$ and $\gamma$ chain sites in platelet aggregation. Proceedings of the National Academy of Sciences, USA, 89: 10729-10732.

40. Fox J W \& Bjarnason J B (1995). Atrolysins: metalloproteinases from Crotalus atrox venom. Methods in Enzymology, 248: 368-387.

41. Ruoslahti E \& Pierschbater MD (1987). New perspectives in cell adhesion: RGD and integrins. Science, 238: 491-497.

42. Timpl R, Paulsson $M$, Dziadek $M$ \& Fujiwara S (1987). Basement membranes. Methods in Enzymology, 145: 363-391.

43. Yurchenco P \& SchittnyJ (1990). Molecular architecture of basement membranes. FASEB J ournal, 4: 1577-1590.

44. Farquhar MG (1991). The glomerular basement membrane: a selective macromolecular filter. In: Hay ED (Editor), Cell Biology of Extracellular M atrix. Plenum Press, New York.

45. Rohrbach DH \& Timpl R (1993). Molecular and Cellular Aspects of Basement Membranes. Academic Press, San Diego.

46. Trygvasson K (1993). The laminin family. Current Opinion in Cell Biology, 5: 877882.

47. Ohsaka A, J ust M \& Habermann E (1973). Action of snake venom hemorrhagic prin- ciples on isolated glomerular basement membrane. Biochimica et Biophysica Acta, 323: 415-428.

48. Orkin RW, Gehron P, McGoodwin EB, Martin GR, Valentine T\& Swarm R (1977). A murine tumor producing a matrix of basement membrane. J ournal of Experimental Medicine, 145: 204-220.

49. Kjellén L \& Lindahl U (1991). Proteoglycans: Structures and interactions. Annual Review of Biochemistry, 60: 443-475.

50. Roberts DD \& Mecham RP (1993). Biology of Extracellular Matrix Series. Academic Press Inc., San Diego.

51. Bernfield M, Kokenyesi R, Kato M, Hinkes MT, Spring J , Gallo RL \& Lose EJ (1992). Biology of the syndecan: A family of transmembrane heparan sulfate proteoglycan. Annual Review of Cell Biology, 8: 365393.

52. Veiga SS, Elias MCQB, Gremski W, Porcionatto MA, Silva R, Nader HB \& Brentani RR (1997). Post-translational modifications of $\alpha_{5} \beta_{1}$ integrin by glycosaminoglycan chains. The $\alpha_{5} \beta_{1}$ integrin is a facultative proteoglycan. J ournal of Biological Chemistry, 272: 1252912535.

53. Elias MCQB, Veiga SS, Gremski W, Porcionatto MA, Nader HB \& Brentani RR (1999). Presence of a laminin-binding chondroitin sulfate proteoglycan at the cell surface of a human melanoma cell Mel-85. Molecular and Cellular Biochemistry, 197: 39-48.
54. Dietrich CP (1984). A model for cell-cell recognition and control of cell growth mediated by sulfated glycosaminoglycans. Brazilian J ournal of Medical and Biological Research, 17: 5-15.

55. Ruoslahti E (1989). Proteoglycans in cell regulation. J ournal of Biological Chemistry, 264: 13369-13372.

56. Buonassisi $\vee \& \&$ Venter JC (1976). Hormone and neurotransmitter receptors in an established vascular endothelial cell line. Proceedings of the National Academy of Sciences, USA, 73: 1612-1616.

57. de Souza GA, Ribeiro AS, Santos VLP, Veiga SS, Mangili OC \& Gremski W (1998). Proteolytic effect of Loxosceles intermedia (brown spider) venom proteins on EHS-basement membrane structures. Acta Biologica Paranaense, 27: 97-109.

58. Bell WR (1990). Defibrinogenating enzymes. In: Colman RW, Hirsh J, Marder VJ \& Salzman EW (Editors), Hemostasis and Thrombosis. Lippincott, Philadelphia, 886-900.

59. Furukawa K \& Ishimaru S (1990). Use of thrombin-like snake venom enzymes in the treatment of vascular occlusive diseases. In: Stocker KF (Editor), Medical Use of Snake Venom Proteins. CRC Press, Boca Raton, 161-173.

60. Soutar RL \& Ginsberg J S (1993). Anticoagulant therapy with ancrod. Clinical Reviews in Oncology and Hematology, 15: 23-33. 